\title{
Cipozeiras e cipozeiros da Mata Atlântica e conflitos ambientais territoriais em Santa Catarina
}

\section{Cipozeiras and cipozeiros of the Atlantic Forest and territorial environmental conflicts in Santa Catarina}

Diego da Silva Grava - Doutor em Sociologia pelo Instituto de Estudos Sociais e Políticos da Universidade do Estado do Rio de Janeiro (IESP-UERJ). Pesquisador do Grupo Interdisciplinar em Pesquisas Socioambientais (Grupo Ipês). E-mail: diego.grava@gmail.com

Luciano Félix Florit- Doutor em Sociologia pela Universidade Federal do Rio Grande do Sul (UFRGS). Professor do Programa de Pós-Graduação em Desenvolvimento Regional da Fundação Universidade Regional de Blumenau (FURB). E-mail: lucianoflorit@gmail.com

Douglas Ladik Antunes - Doutorado em Design pela Pontifícia Universidade Católica do Rio de Janeiro (PUC-Rio). Professor adjunto do Departamento de Design e do Programa de Pós-Graduação em Planejamento Territorial e Desenvolvimento Socioambiental da Universidade do Estado de Santa Catarina (UDESC).E-mail: douglasladik@hotmail.com

\section{Resumo}

Cipozeiras e cipozeiros constituem "comunidades tradicionais" que vivem da extração e do artesanato de diferentes espécies de cipós e de outras atividades de subsistência. Nosso objetivo foi identificar e caracterizar as comunidades em Santa Catarina e verificar a existência de situações de conflitos ambientais. Para isso, efetuamos uma revisão bibliográfica e realizamos, à luz da perspectiva da justiça ambiental, uma reflexão crítica sobre a situação dessas populações no estado. Apresentamos as cipozeiras e os cipozeiros como pertencentes à categoria de "povos e comunidades tradicionais" e evidenciamos que estes grupos vivenciam diferentes conflitos ambientais. Esses conflitos se caracterizam como situações de injustiça ambiental, o que parece um fenômeno comum e recorrente entre os povos e comunidades tradicionais em Santa Catarina e em todo o Brasil.

\section{Palavras-chave}

Cipozeiras e Cipozeiros. Povos e Comunidades Tradicionais. Conflitos Ambientais. Justiça Ambiental. Santa Catarina.

\begin{abstract}
Cipozeiras and cipozeiros constitute "traditional communities" that live from the extraction and craftworks of different species of vines and from subsistence activities. Our aim was to identify the communities living in Santa Catarina state and to verify if they face situations of environmental conflicts. For this, we have done a bibliographical review and carried out, in the light of the perspective of Environmental Justice, a critical analysis about the situation faced by these communities in the state. We present the cipozeiras and cipozeiros as belonging to the category of "traditional peoples and communities"and we show that these groups experience different kinds of environmental conflicts. These conflicts are characterized as situations of environmental injustice, which seems to be a common and recurrent phenomenon among traditional peoples and communities in Santa Catarina and throughout Brazil.
\end{abstract}

\section{Keywords}

Cipozeiras and Cipozeiros. Traditional Peoples and Communities. Environmental Conflicts. Environmental Justice. Santa Catarina. 


\section{INTRODUÇÃO}

Ao longo de muitas gerações, os povos e comunidades tradicionais têm demonstrado que é possível explorar os recursos naturais, para subsistência e para a produção eventual de alguns excedentes, sem gerar danos ambientais significativos, garantindo a reprodução de seu modo vida e a sustentabilidade ambiental de seus territórios tradicionais.

A expansão das fronteiras produtivas (agropecuária, mineral e energética), impulsionada pela valorização das commodities, fez com que atores dominantes, agentes públicos e privados, passassem a fazer incursões em territórios tradicionais a fim de se apropriar de seus recursos naturais (MARTINS, 2009; COMISSÃO ECONÔMICA PARA A AMÉRICA LATINA E O CARIBE [CEPAL], 2012).

Essas incursões ensejaram conflitos em diversas partes do território brasileiro. $\mathrm{O}$ mapeamento mais abrangente sobre esses conflitos foi realizado pela Fundação Oswaldo Cruz (Fiocruz). Até 2010, a Fiocruz (MAPA DE CONFLITOS..., 2010) mapeou mais de 200 casos de conflitos ambientais no país ${ }^{1}$. Nesse mapeamento, há a descrição dos atores envolvidos, as principais causas e os efeitos dos conflitos.

As populações mais atingidas eram indígenas, agricultores familiares, quilombolas, pescadores artesanais, ou seja, predominantemente povos e comunidades tradicionais. Os conflitos se dão sobre os territórios tradicionais, ocasionando alteração no regime de uso e ocupação do território, muitas vezes ocorrendo a expulsão ou reassentamento compulsório desses grupos. Os principais causadores dos conflitos são o agronegócio, a mineração, a construção de barragens e hidrelétricas e a pecuária (MAPA DE CONFLITOS..., 2010).

Dessa forma, esse mapeamento identificou a existência de um padrão de desenvolvimento perverso, que, baseado na exploração intensiva de recursos primários, sobrepõe-se aos direitos e aos modos de vida de povos tradicionais ${ }^{2}$, impactando negativamente tanto estes grupos quanto o meio ambiente.

1 O número atual certamente é muito maior. Somente em Minas Gerais, o Observatório de Conflitos Ambientais (OCA), portal organizado pelo GESTA, catalogou mais de 500 conflitos (OCA, sem data).

2 A noção de modo de vida é utilizada com diversos sentidos nas Ciências Sociais. No contexto deste trabalho, entendemos por modos de vida o conjunto de práticas e saberes que viabilizam a reprodução material e cultural de uma comunidade ou grupo social específico, a partir de uma utilização peculiar dos recursos naturais e do território. Trata-se de uma utilização da expressão ajustada à caracterização de povos e comunidades tradicionais que, via de regra, observam peculiaridades na sua relação com a natureza e o território. No caso dos cipozeiros, seu modo de vida tem como "espinha dorsal" da sua especificidade a utilização do cipó, a partir do qual organizam suas práticas cotidianas e do qual produzem seu sustento e constroem sua identidade, o que permite a sua reprodução material e cultural. Para uma discussão sobre polissemia em torno desta expressão, ver Braga, Fiuza e Remoaldo (2017). 
A conclusão está de acordo com incontáveis investigações realizadas por vários pesquisadores e grupos de pesquisa que vêm observando a situação de povos e comunidades tradicionais. Dentre esses grupos e resultados, podemos citar: a Fiocruz; o Grupo de Estudos em Temáticas Ambientais (GESTAUFGM); o Grupo Interdisciplinar em Pesquisas Socioambientais (Grupo IPÊSFURB); o Grupo de pesquisa Práticas Interdisciplinares em Sociabilidades e Territórios (PEST-UDESC); o Grupo Antropologia, Direitos Humanos e Povos Tradicionais (UFMS); o Grupo de Pesquisa Estado, Hidrelétricas e Conflitos (UFPA); o Núcleo Interdisciplinar de Investigação Socioambiental (NIISAUNIMONTES); e o projeto Nova Cartografia Social.

Desse modo, ressaltamos que a territorialidade urbano-industrialcapitalista, hegemônica na sociedade envolvente, impõe uma forma de racionalidade com relação à natureza. A racionalidade ambiental implica que os "recursos" naturais sejam vistos a partir de uma racionalidade "coisificadora", que reconhece valor a natureza somente nos seus aspectos passíveis de métrica monetária, não considerando relevantes outros atributos. Ao contrário desta lógica, para povos e comunidades tradicionais, ainda que não renunciem ao uso instrumental dos recursos naturais, estes recursos não se reduzem aos aspectos que possibilitam trocas monetárias, e, além disso, associam seus usos a formas de valoração não-instrumentais (FLORIT, 2016).

Santa Catarina (SC) é um estado conhecido por ter uma população majoritariamente branca, de descendência europeia. Todavia, não passou imune a esse processo. Também nesse estado, existem diversos grupos sociais que podem ser chamados de "povos e comunidades tradicionais" e que têm sido igualmente afetados por conflitos ambientais (GRAVA; FLORIT, 2018). Um desse grupos é o das cipozeiras e cipozeiros da região norte de SC. Seu sustento e identidade vêm do trabalho realizado com vários tipos de cipó, da agricultura de subsistência, da caça, da pesca, do trabalho assalariado ou informal. Contudo, os grupos vêm enfrentando cada vez mais obstáculos para acessar os recursos e reproduzir seu modo de vida.

O modo de vida dos cipozeiros está intimamente relacionado com o mundo natural, em especial com a Mata Atlântica. Vivem em grupos familiares e de afinidade que compartilham a atividade extrativista e de artesanato do cipó. A extração do cipó e o artesanato são atividades que ocupam um lugar central em seu modo de vida, conformando o eixo a partir do qual se organiza o tempo e o conjunto de sua 
atividade econômica. São exercidas e lideradas principalmente por mulheres, ainda que muitos homens também participem de todas as etapas produtivas.

A maior parte de sua subsistência é baseada em atividades extrativistas, realizadas por meio do manejo sustentável, sem comprometer a dinâmica dos sistemas regenerativos da Mata Atlântica, bioma ao qual estão adaptados há muitas décadas. Críticos da destruição da natureza, fazem um uso conservacionista dos recursos. Desde a extração dos cipós, ou até mesmo na prática da caça, observam os ciclos naturais, evitando práticas predatórias dos recursos e procurando garantir a regeneração dos recursos - sem os quais não poderiam reproduzir seu modo de vida.

O avanço da urbanização, a construção de rodovias, o desmatamento e a especulação imobiliária vêm representando uma crescente ameaça aos territórios tradicionais dos cipozeiros. Em Santa Catarina e no Paraná, os cipozeiros procuram resistir a esses avanços, organizando-se para garantir o acesso ao território e o reconhecimento de seu modo de vida. Dessa forma, inscrevem-se, de forma peculiar, na mesma problemática de outros povos e comunidades tradicionais constantemente ameaçados pela expansão da territorialidade hegemônica do capitalismo globalizado. Para elas, o território possui uma importância vital, sendo a partir dele que se produz e reproduz sua vida material e simbólica.

O texto apresenta quem são as cipozeiras e os cipozeiros que vivem em Santa Catarina, sua situação socioeconômica e os conflitos ambientais que enfrentam na atualidade, faz uma discussão sobre conflitos ambientais territoriais e conflitos de valoração e discute a categoria de povos e comunidades tradicionais associada à perspectiva da justiça ambiental.

\section{CONFLITOS AMBIENTAIS TERRITORIAIS E DE VALORAÇÃO}

Os conflitos ambientais revelam a existência de diferentes formas de valoração da natureza. As racionalidades das comunidades tradicionais, com suas formas peculiares de valoração da natureza, são em geral ameaçadas pela racionalidade instrumental e homogeneizadora do espaço, hegemônica no capitalismo globalizado. Esta racionalidade "moderna" vê os territórios tradicionais como fornecedores de matéria-prima, alimentos e energia, ignorando o modo de vida e a territorialidade de comunidades ancestrais. Os confrontos, portanto, expressam-se por meio da dimensão territorial. Isso não é diferente no caso das cipozeiras e dos cipozeiros da Mata Atlântica. 
Como a maioria dos povos e comunidades tradicionais, os grupos cipozeiros são pluriativos, conciliando várias formas de produção agrícola e artesanal, sendo apenas parcialmente integrados ao mercado. Possuem um vínculo forte com os locais onde vivem e aos quais se associam formas específicas de uso do território e seus recursos naturais. Esses usos se ajustam aos ciclos naturais e são regulados por regras comunitárias. Dessa dinâmica resulta um modo de produção do espaço e da vida intimamente vinculados com a natureza (FLORIT, 2016).

A situação vivenciada por cipozeiras e cipozeiros da Mata Atlântica também pode ser considerada como uma situação de conflito ambiental territorial. Conforme Laschefski (2011), os conflitos ambientais são resultado da expansão do espaço ambiental de grupos privilegiados. Estes conflitos podem ser classificados em três tipos: 1) espaciais; 2) distributivos; e 3 ) territoriais. Os conflitos espaciais ocorrem nos casos de poluição (sonora, gasosa, hídrica ou de resíduos sólidos) que afetam a qualidade de vida da população que recebe a poluição. Podem ser resolvidos via meios técnicos (filtros, por exemplo) na medida em que estes consigam limitar ao território do próprio gerador o impacto da poluição. Nesse caso, a territorialidade do gerador não compromete a territorialidade do atingido. Os conflitos ambientais distributivos são os que revelam assimetrias nos benefícios decorrentes da apropriação e uso dos recursos e serviços ambientais. A estes cabem somente tratamento por meio de perspectivas ambientalizadas de economia política ou da ecologia política. Nos conflitos ambientais territoriais o que está em jogo é a sobreposição da territorialidade de grupos mais poderosos em territórios de grupos subalternizados, como nos casos de muitas das comunidades tradicionais, sem que sejam oferecidas condições de reproduzir suas relações socioambientais. Neste tipo de conflitos:

as territorialidades de grupos sociais, ou seja, os modos diferenciados de apropriação simbólica e material do meio ambiente, envolvem justamente modos distintos de ver o mundo ou de 'produzir' o espaço que, quando materializados no espaço concreto, se revelam incompatíveis (LASCHEFSKI, 2011, p. 29).

Trata-se, portanto, do resultado de relações desiguais de poder entre aqueles que promovem o modo urbano-industrial-capitalista de produção do espaço e as comunidades locais. No caso das cipozeiras e dos cipozeiros, esse conflito se manifesta principalmente na questão do acesso ao território e pela destruição das matas. 
Assim, os conflitos territoriais evidenciam territorialidades de grupos contrapostos, as quais envolvem também valorações da natureza conflitantes. No caso da territorialidade das comunidades tradicionais, essas valorações permitem lógicas de uso específicas que são diversas da lógica capitalista, que tem como métrica de valoração o parâmetro monetário e que, pela sua integração à economia de mercado, tende a subestimar os atributos que não são traduzíveis a este parâmetro.

Para Martínez-Alier (2007, p. 353), um choque de sistemas de valoração existe "quando os discursos da justiça ambiental, dos direitos territoriais indígenas ou da segurança ambiental se desdobram em oposição à valoração monetária dos riscos e das cargas ambientais".

Conforme Florit, isso acontece porque:

a atribuição de valor monetário, procedimento operacional de valoração no qual todos os valores são reduzidos a uma única escala, só é possível na medida em que algumas qualidades dos entes valorados são consideradas importantes e outras são desconsideradas (FLORIT, 2016, p. 265).

No caso das cipozeiras e dos cipozeiros, sua produção do espaço, embora contenha uma valoração de uso da natureza na medida em que dependem do uso direto desta para atender às suas necessidades vitais, implica em uma combinação complexa de valorações, não apenas instrumentais, que adicionam uma carga de sentido e significação simbólica que é indissociável do uso para o provimento material.

Reconhecer essa carga de sentidos e valorações ajuda a entender por que há algo que esses povos defendem que não é substituível por meio de operações monetarizadas, o que embora esteja conectado com seu suprimento material não se reduz a ele. Isso indica que seu uso da Mata Atlântica, do rio, dos animais, não é apenas o uso de um ambiente produtivo, mas também a defesa de algo ao que se reconhece consideração moral, que não é traduzível em termos monetários e que tem enorme importância quando se pensa sobre as condições para a sustentabilidade dos padrões de desenvolvimento. A restrição ao acesso aos seus territórios e à reprodução de seu modo de vida implica em uma forma de injustiça ambiental.

\section{JUSTIÇA AMBIENTAL NA MATA ATLÂNTICA}

A abordagem da justiça ambiental tem bem demarcados um ponto de vista ético-político e uma base epistemológica. O primeiro ponto deriva de sua 
clara definição de "injustiça ambiental" como imposição de danos ambientais desproporcionais a grupos sociais específicos devido a sua posição social subordinada. O segundo ponto está ligado à tese de que as clivagens sociais predefinem a lógica de distribuição desigual de impactos ambientais e da exposição desigual a ambientes insalubres.

Vários autores apontam que o "Movimento por Justiça Ambiental" (Environmental Justice Movement) teve sua origem nos Estados Unidos, nos anos 1980. Esse movimento resultou da articulação entre lutas de caráter social, territorial, ambiental e de direitos civis (ACSELRAD, sem data; FIGUEROA; MILLS, 2001; HARTLEY, 2003; ACSELRAD; MELLO, BEZERRA, 2009; BULLARD, 2010; LEGARDA; PARDO BUENDÍA, 2011).

A partir da leitura de Robert Bullard, um dos articuladores do movimento, Herculano (2002) define justiça ambiental como:

o conjunto de princípios que asseguram que nenhum grupo de pessoas, sejam grupos étnicos, raciais ou de classe, suporte uma parcela desproporcional das consequências ambientais negativas de operações econômicas, de políticas e programas federais, estaduais e locais, bem como resultantes da ausência ou omissão de tais políticas (HERCULANO, 2002, p. 143).

Portanto, a injustiça ambiental é um mecanismo perverso no qual sociedades desiguais distribuem desproporcionalmente as maiores cargas de danos ambientais a grupos vulneráveis: trabalhadores, pobres, grupos étnicos discriminados e outros (HERCULANO, 2002).

No Brasil, um primeiro marco de sistematização e divulgação dessa problemática está ligado à coleção "Sindicalismo e justiça ambiental", publicada pela Central Única dos Trabalhadores (CUT), nos anos 2000. A consolidação política e acadêmica da perspectiva da justiça ambiental se deu com o "Colóquio Internacional sobre Justiça Ambiental, Trabalho e Cidadania”, realizado em 2001 (HERCULANO, 2002). Já a "Rede Brasileira de Justiça Ambiental" (RBJA) propriamente dita, um espaço de identificação, solidarização e fortalecimento dos princípios de justiça ambiental (BLOG DA RBJA, sem data), firmou-se em 2002.

Assim, a justiça ambiental se encontra na confluência da luta pelos direitos humanos e pela sustentabilidade ambiental. Todavia, vale notar que essa perspectiva padece ainda de algum viés antropocêntrico, mesmo que não no sentido tradicional (RAMMÊ, 2012). Ela não incorpora diretamente considerações do campo da ética ambiental, o qual procura incluir o meio ambiente como objeto de consideração moral. Esse é um aspecto relevante, pois 
povos e comunidades tradicionais, como os cipozeiros, têm a natureza como sujeito de consideração moral.

Como observa Florit (2016, p. 265):

o reconhecimento das múltiplas valorações, concepções socioculturais e lógicas de uso da natureza, encarnadas por sujeitos que sustentam modos de vida tradicionais, é uma condição sine qua non de justiça ambiental em conflitos que envolvem estas populações.

Desse modo, os povos e comunidades tradicionais, como as cipozeiras e os cipozeiros, contribuem para a expansão dos limites da justiça ambiental e para a concretização de uma ética socioambiental, isto é, uma perspectiva que permite incluir humanos e não-humanos como sujeitos passíveis de consideração moral.

\section{CIPOZEIRAS E CIPOZEIROS ENQUANTO COMUNIDADES TRADICIONAIS}

A definição de povos e comunidades tradicionais remete tanto ao âmbito jurídico como ao acadêmico e o político. Juridicamente, os povos indígenas e as comunidades quilombolas gozam de estatuto diferenciado. No entanto, como vimos anteriormente, a denominação "povos e comunidades tradicionais" encontra amparo na legislação brasileira, por meio de uma definição mais abrangente enquanto:

grupos culturalmente diferenciados e que se reconhecem como tais, que possuem formas próprias de organização social, que ocupam e usam territórios e recursos naturais como condição para sua reprodução cultural, social, religiosa, ancestral e econômica, utilizando conhecimentos, inovações e práticas gerados e transmitidos pela tradição (BRASIL, 2007, sem página).

O Decreto $\mathrm{n}^{\circ}$ 6.040, de 7 de fevereiro de 2007 (BRASIL, 2007), que institui a Política Nacional de Desenvolvimento Sustentável dos Povos e Comunidades Tradicionais, consolida e reconhece oficialmente a categoria de povos e comunidades tradicionais. Adicionalmente, o decreto traz a definição de territórios tradicionais como sendo "os espaços necessários a reprodução cultural, social e econômica dos povos e comunidades tradicionais, sejam eles utilizados de forma permanente ou temporária" (BRASIL, 2007). Portanto, o decreto reconhece a importância do território para a reprodução material e cultural dos povos e comunidades tradicionais. 
As cipozeiras e os cipozeiros fazem parte dessa realidade, tanto que o Conselho Nacional dos Povos e Comunidades Tradicionais (CNPCT), instituído pelo Decreto n⿳ำ 8.750, de 9 de maio de 2016 (BRASIL, 2016), garante aos cipozeiros o direito à representação ${ }^{3}$. A Lei Municipal no 1981, de 28 de abril de 2017 (GARUVA, 2017), reconhece, por meio de certificado, a existência social dos grupos denominados Povos e Comunidades Tradicionais no município de Garuva.

No âmbito acadêmico e político, a definição "povos e comunidades tradicionais", talvez por sua amplitude e "imprecisão", levou alguns autores a serem críticos ou a fazerem ressalvas ao uso da categoria (DIEGUES, 2000; LITTLE, 2004; BRANDÃO, 2015; COSTA FILHO, 2015).

Nesse contexto, Brandão (2015) faz uma primeira e importante distinção sobre a diferenciação entre sociedade e comunidade. De modo resumido, o autor afirma que a sociedade seria o lugar mais abstrato, abrangente, institucional, contratual e impositivo, enquanto que a comunidade seria o lugar do concreto, delimitado, interpessoal, consensual e livre. Assim, no plano analítico, as comunidades tradicionais seriam uma contraposição à sociedade moderna, implicando em uma lógica de organização social distinta, com características próprias, resguardando certa autonomia.

Essa distinção é relevante para compreender as cipozeiras e os cipozeiros, uma vez que sua dinâmica comunitária é severamente afetada pela dinâmica da sociedade envolvente, a qual não reconhece sua territorialidade e modo de vida peculiar, dependente do território e seus recursos naturais.

Outra diferenciação importante, observada por Brandão (2015), é aquela entre comunidades tradicionais e comunidades indígenas. O desenvolvimento da modernidade rompeu e ressignificou antigas tradições, dissolvendo muitas comunidades e instituições tradicionais. Nesse cenário, as comunidades tradicionais foram incorporadas ou afetadas pelo processo de modernização, tornando-se dependentes e/ou subordinadas (econômica e politicamente) em relação à sociedade moderna. Isso seria evidente com as comunidades indígenas que, ao contrário, seriam autônomas e independentes, o que as colocaria em uma categoria diferente das demais. No entanto, o mesmo vale para outros tipos comunidades tradicionais que compartilham essas características.

As cipozeiras e os cipozeiros, descendentes de negros, índios e brancos, apresentam um modo de vida peculiar, bastante diferente daquele da sociedade moderna envolvente. Ainda que mantenham vínculos e trocas com ela, mantêm

Embora até o presente ainda não tenham indicado nenhum representante. 
práticas tradicionais que são passadas de geração em geração e são diretamente dependentes dos recursos naturais disponíveis em seus territórios tradicionais.

Já nos referimos ao baixo impacto ambiental dessas comunidades. Para Cunha e Almeida (2001), a categoria remete aos grupos sociais que têm histórico de impacto ambiental reduzido e possuem interesse em manter e controlar os territórios que exploram, prestando em troca serviços ambientais. Ademais, em geral, apresentam formas de organização social mais equitativas, lideranças locais, instituições próprias ${ }^{4}$ e traços culturais selecionados que são reelaborados e reafirmados continuamente (especialmente em situações de conflito ou na luta pelo reconhecimento de direitos). Nesse contexto, vale notar a resposta da sra. Marlene, ao ser indagada sobre o que ela era: “eu sou uma cipozeira. Eu não posso dizer outra coisa, porque eu sou cipozeira” (CIPOZEIROS, 2012).

Brandão (2015) segue o mesmo raciocínio reafirmando algumas das categorias observadas por Cunha e Almeida (2001) e incluindo outras, como a memória de resistência (principalmente com referência a processos ligados ao território, como ameaça, expulsão e expropriação).

Embora existam diferenças profundas entre elas, é possível observar traços comuns quanto às suas "práticas produtivas tradicionais" sustentáveis e a visão de natureza não apenas instrumental (GRAVA, 2017). Também em comum, essas comunidades apresentam uma relação estreita com o território, adotam modos de produção artesanais e de baixo impacto ambiental. Ainda que não estejam totalmente fora da lógica de mercado, não podem ser equiparados a outros atores econômicos, como empresas privadas ou estatais. Como verificamos entre as cipozeiras e os cipozeiros, existe uma preocupação com a regeneração dos recursos e uma série de interdições ao uso da natureza que impedem seu uso meramente instrumental. Atualmente, realizam trocas comerciais para suprirem uma série de necessidades, o que era muito menos frequente "no tempo dos antigos", quando havia maior disponibilidade de matéria-prima e o acesso aos territórios era livre.

Nesse contexto, vale destacar a importância e a centralidade do cipó para o modo de vida cipozeiro. Apesar de serem pluriativos, dedicando-se à agricultura, à criação de animais, à pesca, atividades que servem de subsistência e para troca (escambo), sua fonte de renda vem da venda do artesanato, da qual

4 Referindo-se à existência de instituições que possuem legitimidade e fazem cumprir suas leis (CUNHA; ALMEIDA, 2001).

5 "No tempo dos antigos" é um termo comumente utilizado por cipozeiras e cipozeiros ao fazer menção à história de seus antepassados, quando remontam ao tempo em que tinham direito de livre acesso ao território para o manejo de cipó e de outros recursos. 
obtêm dinheiro. Além disso, sua identidade tem o cipó como "espinha dorsal", reconhecendo-se, antes de tudo, como cipozeiras e cipozeiros.

As formas das peças expressam também a tensão existente com os atravessadores. Eles manifestam a preferência de fazer o artesanato com fundo trançado, em contraposição às peças com fundo de compensado, apesar de ser mais difícil de fazer, pois se exige mais trabalho. Em trabalho de campo ${ }^{6}$, uma artesã destacou a preferência coletiva por estas "peças tradicionais", "naturais", e certa aversão às peças mais artificiais com fundo pronto de compensado. $\mathrm{O}$ fundo é fornecido pelos atravessadores que encomendam as peças, exigindo altas quantidades em pouco tempo e a preços baixos. A fala demonstrava uma valorização da forma tradicional das peças que expressam um conteúdo mais identitário e um repúdio à produção que expressa uma tendência industrial. Para eles, o uso de compensado representa uma sujeição do modo de vida tradicional ao mercado ou à produção urbana, o que novamente remete à valorização do natural associado ao modo de vida tradicional e à identidade cipozeira.

Considerando a contribuição de vários autores, elencamos uma série de características comuns que permitem identificar os povos e comunidades tradicionais: autorreconhecimento; conexão forte com o território; conhecimentos e práticas transmitidos pela tradição; dependência dos recursos naturais para reprodução material e social; diferenciação cultural; histórico de baixo impacto ambiental; lideranças locais; ligação diferenciada com o mercado; memória de resistência (ligada à permanência no território); organização social mais equitativa; reduzida acumulação de capital; representação institucional; trabalho "informal"; traços culturais selecionados e reelaborados e reafirmados continuamente (CUNHA; ALMEIDA, 2001; BRASIL, 2007; BRANDÃO, 2015). As comunidades cipozeiras compartem todas essas características com outros povos e comunidades tradicionais, ao que se pode afirmar que se caracterizam como uma comunidade tradicional.

Embora utilizada rotineiramente, a natureza não é vista pelos grupos cipozeiros apenas de modo instrumental, fazendo parte do seu círculo de consideração moral (GRAVA, 2017). Assim, os grupos têm contribuído para a conservação da qualidade ambiental de seus territórios por meio de práticas tradicionais que vêm se reinventando diante da expansão urbana e agropecuária, estabelecendo alianças (com organizações, pesquisadores e outros grupos cipozeiros) e conflitos (com empresas e o Estado) na luta pelo direito de acessar seus territórios tradicionais e para manter seus modos de vida.

${ }_{6} \quad$ Realizado entre 4 e 6 de maio de 2018, em uma oficina com uma família de Garuva (SC). 


\section{CIPOZEIRAS E CIPOZEIROS EM SANTA CATARINA: CARACTERIZAÇÃO E CONFLITOS AMBIENTAIS}

Os cipozeiros são grupos vivem da extração de diferentes espécies de cipó, sendo o imbé o principal, e o vendem em estado bruto ou o utilizam para a confecção de artesanato (cestos, balaios, chapéus, luminárias, artigos de decoração). Complementam a renda com outras atividades, incluindo a extração de outros recursos florestais, a agricultura de subsistência, a caça, a pesca e o trabalho assalariado, em geral informal (bicos).

Segundo a linha do tempo de Venturi et al. (2006), a utilização do cipó imbé teria iniciado no começo do século XX, originalmente por índios Carijó ou Guarani Mbya. Foi somente a partir de 1909 que teve início a exploração comercial. Até os anos 1960, o extrativismo do cipó era livre, além da caça, do palmito, da pesca - práticas que ainda hoje fazem parte do repertório cultural dos cipozeiros. Originalmente, o artesanato do cipó se dava no âmbito doméstico, quase não havia comércio e os recursos eram abundantes.

Nos anos 1970 teve início a comercialização de artesanato feito de cipó em Guaratuba (PR). Posteriormente, a prática passou a ser realizada em outros lugares. Em 1980, o acesso à mata, que ficava em fazendas fechadas, passou a ser restrito. Também devido ao crescente desmatamento, o recurso começou a se tornar escasso. Entre 1985 e 1989, chegou-se ao auge do artesanato, com muito comércio e preços atrativos para os artesãos. Entre 1996 e 2000, ocorreu a primeira tentativa de se formar uma cooperativa, a qual se concretizou em 2000, por meio de financiamento da prefeitura de Guaratuba. A partir dos anos 2000, a Empresa de Pesquisa Agropecuária e Extensão Rural de Santa Catarina (Epagri) passou a influenciar o processo produtivo, levantando questões sobre a segurança do trabalho.

Em pesquisas feitas desde 2007, revela-se que no passado os cipozeiros produziam objetos apenas para uso próprio. Teria sido somente nos anos 1970, devido à forte influência do trânsito nas rodovias locais, trazendo clientes potenciais, que grupos teriam começado a comercializar o artesanato do cipó, além de outros produtos da roça.

Quanto ao processo produtivo com o cipó, de maneira resumida, este se dá da seguinte maneira:

Philodendron corcovadense Kunth - ARACEAE (ALMEIDA; ACEVEDO MARIN; SHIRAISHI NETO, 2007; RAMOS et al., 2017). 
1. Inicia-se com o deslocamento até a mata, onde se faz a extração do cipó. Este deve estar maduro e, além disso, não se pode tirar todos os cipós de uma árvore para não colocar em risco a "mãezera" (a "planta mãe" que dá o cipó). Os cipozeiros afirmam que antigamente era fácil acessar os locais de extração. Atualmente, lidam com vários obstáculos, como a distância (até duas horas de caminhada pela mata), redução da matéria-prima (efeito do desmatamento), dificuldade para acessar as propriedades (que são privadas);

2. Depois da extração, há que se carregar o cipó bruto para fora da mata. Os cipós são organizados em feixes que podem chegar a pesar até $60 \mathrm{~kg}$. Em média, pesam entre 10 e $20 \mathrm{~kg}$. Esse trabalho é realizado por homens e mulheres;

3. O cipó é então armazenado em local próprio, em casa. Pode ser utilizado bruto ou beneficiado, o chamado "cipó branco". Para o beneficiamento, o cipó deve ser descascado, uma tarefa árdua, que exige destreza e resistência física. Em seguida, são deixados num telhado ou outra superfície para escorrer o líquido interno e secar;

4. Já seco, os cipós brancos são manipulados em um "gabarito" para se chegar à espessura adequada. Esse gabarito é uma caixa elaborada artesanalmente pelos cipozeiros. Esse procedimento é denominado de "passar o cipó";

5. Após esses processos, as peças de artesanato, de cipó bruto ou branco, são elaboradas e posteriormente são vendidas na beira de estrada, a atravessadores ou em feiras (GLOBO ECOLOGIA..., 2010a; 2010b; ANTUNES, 2011; GRAVA et al., 2019).

Entre os cipozeiros, mais do que uma diferenciação, existe uma oposição entre aqueles que se consideram "cipozeiros tradicionais" e os chamados de "cipozeiros da cidade", alguns vistos como oportunistas. Os tradicionais são aqueles que, há várias gerações, demonstram preocupação com o meio ambiente. Já os oportunistas são aqueles que somente extraem o cipó para venda e não fazem o manejo considerado correto pelos cipozeiros tradicionais, isto é, de modo que permita a regeneração do recurso (ALMEIDA; ACEVEDO MARIN; SHIRAISHI NETO, 2007; ANTUNES, 2011).

Os cipozeiros são descendentes de indígenas, negros e europeus (alemães, poloneses, italianos e portugueses) ${ }^{8}$. Os grupos estão predominantemente localizados na região norte de Santa Catarina, mas também no sul do Paraná.

8 Conforme relatos de cipozeiras, como Ruth Gonçalves (GLOBO ECOLOGIA..., 2010a; ANTUNES, 2011) e Judith Lopes de Souza (relato pessoal durante entrevista realizada em 15 de maior de 2019). 
Há indicações da presença no norte de São Paulo, porém não se encontram informações precisas sobre estes grupos. Em todo o país, calcula-se que existem aproximadamente 10.000 pessoas que se identificam como cipozeiras. Em Santa Catarina, existem grupos em Joinville, Araquari, Itapoá e, principalmente, Garuva. O Mapa 1 mostra a localização dos grupos nesse estado:

Mapa 1 - Cipozeiras e cipozeiros em Santa Catarina.

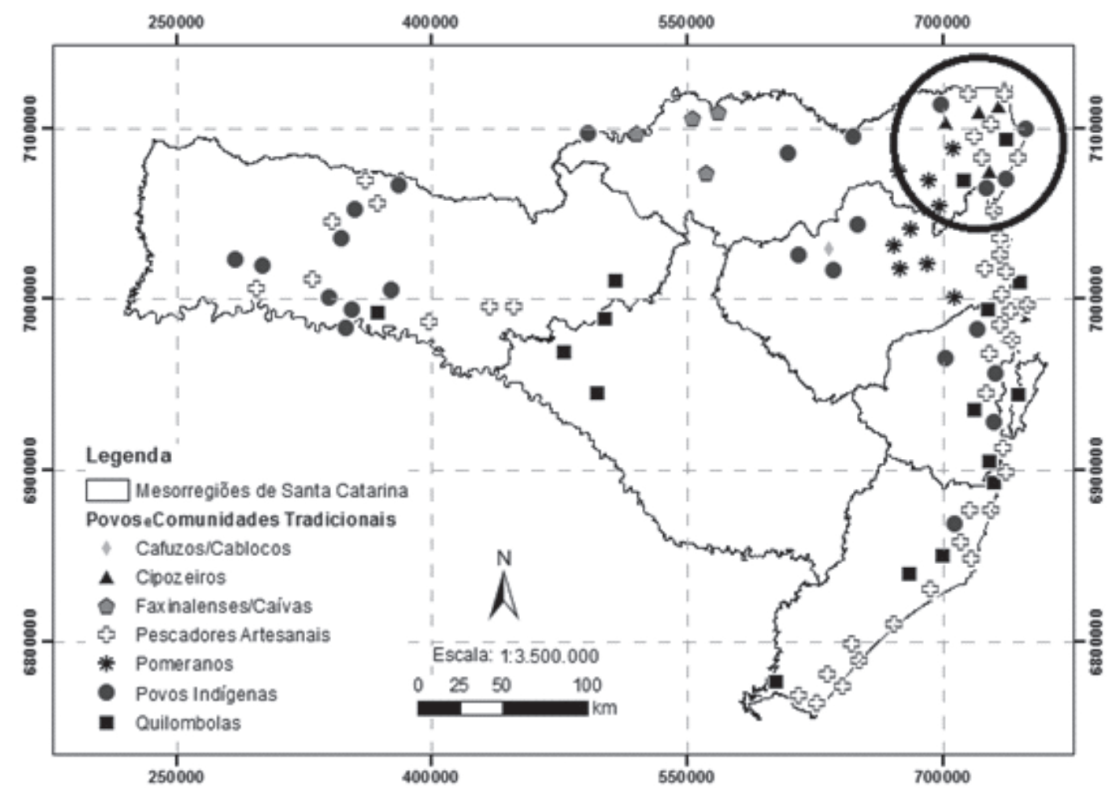

Fonte: Elaborado por Patrícia Scaburri do LabGeo, FURB, 2019.

Garuva é o município onde há a maior concentração de cipozeiras e cipozeiros, entre 200 e 300 famílias (ALMEIDA; ACEVEDO MARIN; SHIRAISHI NETO, 2007; GLOBO ECOLOGIA..., 2010a; 2010b; ANTUNES, 2011; BUSTAMANTE; CABRAL; SILVA, 2015; MMA, 2016).

A extração e o beneficiamento do cipó são atividades essencialmente coletivas e passadas de geração a geração. Um informante de Garuva: "mesmo que a gente fique rico, a gente continua tirando cipó, porque é feito uma terapia, um costume, fica todo mundo junto, a família junta" (ALMEIDA; ACEVEDO MARIN; SHIRAISHI NETO, 2007, p. 3). Portanto, mais do que uma forma de gerar renda, a prática é uma atividade socialmente relevante, até por que os produtos têm baixo valor agregado. Isto faz com que haja uma tendência de exploração predatória, principalmente pelos "oportunistas", e coloca as famílias em situação de vulnerabilidade socioeconômica (CIPOZEIROS, 2012; RAMOS et al., 2017). 
A renda média adquirida por família é relativamente baixa, como apontam dados de um pré-cadastramento realizado pela Epagri ${ }^{9}$. Em 2006, essa renda era de $\mathrm{R} \$ 316,50$, trabalhando em média 10 horas por dia, de cinco a sete dias da semana, dependendo da família. Nesse período, o salário mínimo era de R $\$$ 510,00 (BRASIL, 2010).

Nesse pré-cadastramento, no ano de 2006, 22 famílias foram cadastradas como cipozeiras. Destas, apenas cinco não tinham outras atividades. A maioria, portanto, complementava a renda com outras atividades. Dentre estas, estão práticas tradicionais (roça de mandioca e outras espécies vegetais), pesca, coleta de caranguejo, produção de mudas de palmeira real e eucalipto e prestação de serviços no mercado de trabalho formal e informal (servente de pedreiro, chapeiro, servente de escola, comerciante, venda em bancas de estrada, aposentados, artesanato de vime e chacareiro).

Assim, o conjunto dos dados indica que, além da vulnerabilidade econômica das famílias, a realização da atividade transcende a uma racionalidade meramente instrumental de exploração da natureza, com o objetivo de aferir lucro.

Atualmente, os cipozeiros continuam enfrentando diversos obstáculos para a manutenção de seu modo de vida. Os principais são: restrições jurídicas, ambientais, sociais, econômicas. Uma queixa recorrente é a falta de licenciamento. A falta de segurança jurídica, de permissão para que possam adentrar as matas e extrair o cipó livremente, faz com que os cipozeiros se sintam ameaçados com a possibilidade de punição por órgãos ambientais (ALMEIDA; ACEVEDO MARIN; SHIRAISHI NETO, 2007).

As áreas onde fazem a extração vêm diminuindo gradativamente e geralmente são propriedade de grandes empresas. O desmatamento vem substituindo as áreas de floresta por monoculturas de pinus, eucalipto, arroz, banana e pastagens. Em muitas áreas onde encontram o cipó, têm que pedir autorização para entrar, em alguns casos é necessário pagar uma taxa, do contrário têm que se arriscarem a invadir as propriedades, enfrentando até mesmo conflitos armados. Outras áreas sensíveis são aquelas ricas em palmito, pois os cipozeiros costumam ser confundidos com "palmiteiros" ou caçadores ilegais (ALMEIDA; ACEVEDO MARIN; SHIRAISHI NETO, 2007).

\footnotetext{
A Empresa de Pesquisa Agropecuária e Extensão Rural de Santa Catarina, através de seu escritório municipal coordenado à época pela extensionista Roberta Ramos, aplicou os questionários de pré-cadastramento nas famílias cipozeiras em parceria com pesquisadores da Universidade do Estado de Santa Catarina (UDESC).
} 
Além dessas dificuldades, a concorrência com "extratores oportunistas" agrava sua situação. Ademais de não respeitarem os ciclos naturais, de modo a garantir a regeneração dos cipós - observando as "boas práticas" de extração -, alguns oportunistas adulteram o peso dos feixes de cipó com pedras e hidratando o feixe, gerando uma má reputação que prejudica os cipozeiros tradicionais. Consequentemente, tem-se o prejuízo ambiental e os grupos tradicionais acabam sendo confundidos com oportunistas, cujo contexto de conflitos vem sendo registrado desde a elaboração do Fascículo de Cartografia Social (ALMEIDA; ACEVEDO MARIN; SHIRAISHI NETO, 2007).

Estes e outros fatos fizeram com que os cipozeiros se organizassem de forma coletiva. Em 2004, criaram uma associação, o "Núcleo Cipó Imbé”, em parceria com artesãos, extratores, extensionistas e pesquisadores. O objetivo desse núcleo é articular ações em áreas de manejo sustentável, do "design” integral e da economia solidária (ALMEIDA; ACEVEDO MARIN; SHIRAISHI NETO, 2007). Também estão organizados em torno do "Movimento Interestadual de Cipozeiros e Cipozeiras" (MICI), criado em 2008. Esse movimento mobiliza grupos de Santa Catarina e do Paraná. Os cipozeiros também se articulam com a Rede Puxirão, a qual congrega diversos povos e comunidades tradicionais na luta por seus direitos territoriais.

Os cipozeiros tradicionais demonstram grande cuidado na extração do cipó, retirando somente aqueles que estejam maduros, realizando um esquema de "pousio", permitindo a regeneração das raízes (ALMEIDA; ACEVEDO MARIN; SHIRAISHI NETO, 2007; ANTUNES, 2011).

A tese de doutorado de Antunes (2011) retrata com maior profundidade aspectos do modo de vida e das situações sociais vividas pelo grupo social aqui tratado. Porém, em trabalhos mais recentes, que se articulam a partir de atividades de extensão de pesquisadores da UDESC e FURB desde 2018, verifica-se que muitas das situações relatadas ainda prevalecem, conforme se pode observar em Grava et al., 2019.

Segundo Antunes e Souza (2012), os cipozeiros teriam se adaptado de modo único ao território em que vivem, utilizando técnicas e tecnologias próprias à sobrevivência naquela localidade. Em muitas ocasiões, fazem referências "aos antigos", demonstrando a ancestralidade de seu modo de vida. Conforme relata, existia o regime de "matirão"10, no qual uns ajudam aos outros no trabalho

10 O termo "matirão" é empregado em Garuva com o mesmo significado de "mutirão. Existe ainda o "matirão pitoco" e o "matirão não-pitoco", sem festa e com festa, respectivamente. 
coletivo na roça. Uma informante também comenta sobre o abate de porco, o qual era feito em mutirões e em que a carne era dividida entre a coletividade.

Essa mesma informante afirma que, antigamente, eles todos tinham acesso aos recursos da floresta, usando tudo o que a natureza lhes dava. Atualmente, em saídas ao campo nas oficinas de manejo, observa-se que uma ampla gama de recursos naturais ainda é utilizada. A prática da agricultura de subsistência, da pesca e da caça fazem parte do modo de vida cipozeiro. Quanto à extração de madeira, relatam que antigamente havia o costume de cortar a madeira tanto para uso como para a venda, não se desmatando além do necessário, mantendose o restante da mata nativa. Contudo, várias práticas tradicionais foram sendo cerceadas por conta da legislação e da fiscalização, o que é motivo de insatisfação e insegurança entre os cipozeiros.

Desde o "tempo dos antigos" a caça é realizada durante a extração do cipó, mas não exclusivamente. Para essa prática, utilizam cachorros especialmente treinados para isso. Um cachorro considerado bom é aquele que alerta para a presença de cobras. Além disso, devem ter a habilidade de pegar uma presa específica, como tatu ou quati.

Os relatos de alguns informantes indicam a valoração da natureza dos cipozeiros. Para eles, a natureza é algo do qual as pessoas fazem parte e não pode ser apropriada privadamente. Em 2007, um informante relatou: "o que é da natureza é de todo mundo". Outra informante fez uma afirmação semelhante: "Isso aqui, esse mato, esse rio, tudo que você vê daqui, é nosso, porque faz parte da nossa vida" (ANTUNES, 2011, p. 135). Dessa forma, afirmam que a natureza é um bem coletivo, e não privado.

Sobre a necessidade da proteína animal, uma informante relatou, em 2006: "sei quando posso tirar uma paca, por exemplo agora não é época de paca, ela tá prenha" (ANTUNES, 2011, p. 166). Vale notar que, considerando as restrições legais, os informantes evitam o assunto da caça. Entretanto, essa informante enfatizou que também na caça, realizada apenas para consumo próprio, eles têm cuidado com a preservação e retirando somente o necessário para a alimentação. A carne é dividida entre os vizinhos. $O$ fato demonstra que existe uma restrição ao abate dos animais. Disso, pode se depreender que não se trata de um mero uso instrumental dos animais de caça e que os cipozeiros têm uma forma específica de tratar da sustentabilidade ambiental, associada a seu modo de vida.

Atualmente ainda se observa que os cipozeiros tradicionais são críticos à redução dos recursos naturais, à dificuldade de acesso às matas e aos danos 
ambientais causados pelas monoculturas, ao uso de agrotóxicos, e à construção de rodovias. Outro motivo de crítica e insatisfação são as pessoas que extraem o cipó de "maneira incorreta", sem respeitar o ciclo de renovação do recurso e dificultando o trabalho daqueles que buscam fazer o manejo correto.

Os tipos de conflito enfrentados variam de comunidade para comunidade. Entre aqueles registrados no Mapeamento Situacional, entre 2009 e 2010 ${ }^{11}$, os principais são: fiscalização ambiental - a qual afeta mais as comunidades cipozeiras do que os grandes proprietários, segundo o relato dos cipozeiros; falta de matéria-prima; preço baixo/injusto (deixando-os vulneráveis); distância para se chegar ao recurso (e em terreno de difícil acesso); repressão/acesso restrito por "jagunços" (inclusive pistoleiros); desmatamento; grilagem/golpes/expulsão; especulação imobiliária; monoculturas; falta de compradores; exploração da mão de obra (associada ao preço baixo pago pelos produtos).

Há que se ressaltar que a restrição ao acesso ao território é a situação mais grave. Essa inviabiliza sua subsistência, impedindo a manutenção e reprodução do modo de vida cipozeiro. Durante nossa participação em uma oficina com cipozeiros de Garuva, realizada entre 4 e 6 de maio de 2018, e também em uma entrevista realizada em 15 de maio de $2019^{12}$, os cipozeiros reafirmaram várias das dificuldades relatadas aqui, embora não estejam sofrendo nenhum tipo de perseguição. Na entrevista, uma liderança cipozeira comentou que a maior dificuldade no momento tem sido o processo de reconhecimento jurídico dos cipozeiros como comunidade tradicional. Apesar da Lei nº 1981/2017 ter sido aprovada pelos vereadores do município, falta ainda o trâmite da Certidão de Autorreconhecimento encaminhado ao Executivo para elaboração de lei municipal que possa beneficiar as comunidades cipozeiras.

\section{CONCLUSÕES}

O conjunto de dados encontrados até aqui permitem compreender que os cipozeiros se enquadram na categoria de comunidade tradicional, com suas características e percurso histórico próprios. Vimos que os cipozeiros utilizam

11 Foram oito meses de levantamento, com entrevistas a informantes de 46 famílias em cinco municípios, totalizando 23 comunidades analisadas. $\mathrm{O}$ autor registrou a existência de 534 famílias cipozeiras, sendo 385 somente em Santa Catarina, distribuídas da seguinte forma: 149 em Guaratuba (PR); 281 em Garuva (SC); 46 em Joinville (SC); 28 em Araquari (SC); e 20 em Itapoá (SC) (ANTUNES, 2011).

12 Os relatos sobre a participação nessa oficina e a entrevista foram apresentados no $19^{\circ}$ Congresso Brasileiro de Sociologia, em 2019 (GRAVA et al., 2019). 
a natureza de maneira não meramente instrumental e que eles apresentam preocupações com a sustentabilidade ambiental. Além disso, assim como outros povos e comunidades tradicionais, passam por situações de conflitos ambientais, em especial com relação ao acesso aos territórios e seus recursos, os quais permitem a reprodução de seu modo de vida.

Portanto, a partir das teses da justiça ambiental, de que as desigualdades sociais predefinem a lógica de distribuição desigual do acesso aos recursos naturais e dos impactos decorrentes de seu uso, o trabalho procurou verificar a situação dos cipozeiros em Santa Catarina. Considerando que os grupos dependem da exploração direta dos recursos naturais existentes em seus territórios de modo a manter a produção e reprodução de sua vida material e simbólica, a situação de conflito ambiental representa uma ameaça a seus modos de vida.

Por meio da revisão bibliográfica e de uma curta incursão em campo, atestamos que os cipozeiros têm passando por situações de conflitos ambientais territoriais. Estas situações estão ligadas principalmente à falta de garantia de acesso aos territórios e aos recursos, por ameaças ambientais - que inviabilizam a produção de forma tradicional e a reprodução de seu modo de vida - e pela demora de o poder público em reconhecer sua identidade e modo de vida.

Os poucos estudos sobre os cipozeiros, principalmente nas Ciências Sociais, é um indicador de que eles se encontram invisibilizados. Esse fato mostra a urgência e relevância de se produzir conhecimento sobre eles, seja em Santa Catarina ou no Paraná. Mais do que isso, indica que a formulação de políticas públicas que atendam especificamente e de modo satisfatório as suas necessidades é de extrema importância.

Assim como os demais povos e comunidades tradicionais, os cipozeiros apresentam premissas éticas socioambientais, colocando limites morais aos usos da natureza. Dessa forma, contribuem para a sustentabilidade ambiental de seus territórios. Suas lutas territoriais implicam uma ontologia distinta, não dualista, a qual dá origem a valorações incomensuráveis do ponto de vista da sociedade envolvente. É preciso reconhecer essas concepções e as valorações associadas e, principalmente, reconhecer e garantir seus direitos territoriais. Essas concepções e valorações oferecem exemplos de usos da natureza associados à sua consideração moral, constituindo uma contribuição enorme no sentido que produzimos uma ética socioambiental satisfatória, ou seja, uma perspectiva que considera os interesses de seres humanos e não-humanos, fazendo prevalecer a justiça ambiental. 


\section{AGRADECIMENTOS}

Os autores agradecem ao CNPq, à FAPESC e à ACAFE pelo financiamento da pesquisa; a Patrícia Scaburri e ao LabGeo-FURB pela elaboração do mapa; aos pareceristas anônimos, pelos comentários e sugestões; e às cipozeiras e cipozeiros de Garuva, pela acolhida e pelos ensinamentos.

\section{REFERÊNCIAS}

ACSELRAD, H. Justiça ambiental - novas articulações entre meio ambiente e democracia. Sem data. Disponível em: http://www.ettern.ippur.ufrj.br/publicacoes/71/ justica-ambiental-novas-articulacoes-entre-meio-ambiente-e-democracia. Acesso em: 24 maio 2016.

ACSELRAD, H.; MELLO, C. C. A.; BEZERRA, G. N. O que é justiça ambiental? Rio de Janeiro: Editora Garamond, 2009.

ALMEIDA, A. W. B.; ACEVEDO MARIN, R. E.; SHIRAISHI NETO, J. (Coord.). Cipozeiros de Garuva: Floresta Atlântica, Santa Catarina. Florianópolis: Projeto Nova Cartografia Social dos Povos e Comunidades Tradicionais do Brasil, 2007. 11 p. (Fascículo, 9).

ANTUNES, D. L. Cipozeiros em movimento: cultura material, conflitos territoriais e relações educativas em design. 2011. Tese (Doutorado em Design) - Programa de Pós-Graduação em Design, Pontifícia Universidade Católica do Rio de Janeiro, Rio de Janeiro, 2011.

ANTUNES, D. L.; SOUZA; R. M. No "tempo dos antigos": objetos e práticas tradicionais como afirmação dos cipozeiros. In: MARTINS, P.; SÁNCHEZ, H. Á; WELTER, T. (Orgs.). Território e sociabilidade: relatos latino-americanos. Florianópolis: Editora da UDESC, 2012. p. 229-252.

BLOG DA REDE BRASILEIRA DE JUSTIÇA AMBIENTAL [RBJA]. Sobre a RBJA. Blog da RBJA, sem data. Disponível em: https://redejusticaambiental.wordpress.com/ sobre/. Acesso em: 05 jul. 2019.

BRAGA, G. B.; FIUZA, A. L. C.; REMOALDO, P. C. O conceito de modo de vida: entre traduções, definições e discussões. Sociologias, Porto Alegre, v. 19, n. 45, p. 370-396, 2017.

BRANDÃO, C. R. A comunidade tradicional. In: UDRY, C.; EIDT, J. S. (Ed.). Conhecimento tradicional: conceitos e marco legal. Brasília: Embrapa, 2015. p. 21 101. (Coleção Povos e Comunidades Tradicionais).

BRASIL. Decreto $n^{\circ}$ 6.040, de 7 de fevereiro de 2007. Institui a Política Nacional de Desenvolvimento Sustentável dos Povos e Comunidades Tradicionais. Diário Oficial da União. Brasília, DF: Presidência da República, 2007. Disponível em: http:/ /www.planalto. gov.br/ccivil_03/_ato2007-2010/2007/decreto/d6040.htm. Acesso em: 22 ago. 2019. 
BRASIL. Lei no 12.255, de 15 de junho de 2010. Dispõe sobre o salário mínimo a partir de $1^{\circ}$ de janeiro de 2010 [...]. Diário Oficial da União. Brasília, DF: Presidência da República, 2010. Disponível em: http://www.planalto.gov.br/ccivil_03/_Ato20072010/2010/Lei/L12255.htm. Acesso em: 22 ago. 2019.

BRASIL. Decreto $n^{\circ}$ 8.750, de 9 de maio de 2016. Institui o Conselho Nacional dos Povos e Comunidades Tradicionais. Diário Oficial da União. Brasília, DF: Presidência da República, 2016. Disponível em: http://www.planalto.gov.br/ccivil_03/_Ato20072010/2010/Lei/L12255.htm. Acesso em: 22 ago. 2019.

BULLARD, R. D. Environmental justice for all. In: KELLER, D. R. Environmental ethics: the big questions. Blackwell Publishing, 2010. p. 491-500.

BUStamante, A. M. G.; CABRAL, D. C.; SILVA, J. K. T. Patrimônio ambiental e diversidade cultural do Brasil. In: UDRY, C.; EIDT, J. S. (Ed.). Conhecimento tradicional: conceitos e marco legal. Brasília: EMBRAPA, 2015. p. 103-159. (Coleção Povos e Comunidades Tradicionais).

CIPOZEIROS. [S. l.: s. n.], 2012. 1 vídeo. (3 min). Publicado pelo canal TV Univali. Disponível em: https://www.youtube.com/watch?v=1suF3sA9S8Y. Acesso em: 25 jul. 2012.

COMISSÃO ECONÔMICA PARA A AMÉRICA LATINA E O CARIBE [CEPAL]. Anuario Estadístico de América Latina y el Caribe. Santiago del Chile: Nações Unidas, 2012. Disponível em: http://www.eclac.cl/publicaciones/xml/4/48864/ AnuarioEstadistico2012_ing.pdf. Acesso em: 08 de jul. 2013.

COSTA FILHO, A. O processo de construção dos povos e comunidades tradicionais no Brasil. Kooperation Brasilien, 05 nov. 2015. Disponível em: https://www.kooperationbrasilien.org/de/themen/menschenrechte-gesell-schaft/traditionelle-voelkergemeinschaften/o-processo-de-construcao-dos-povos-e-comunidades-tradicionais-nobrasil. Acesso em: 22 ago. 2019.

CUNHA, M. C.; ALMEIDA, A. W. B. Populações tradicionais e conservação ambiental. In: CAPOBIANCO, J. P. R.; VERÍSSIMO, A.; MOREIRA, A.; SANTOS, I; PINTO, L. P. (Orgs.). Biodiversidade na Amazônia brasileira: avaliação e ações prioritárias para a conservação, uso sustentável e repartição de benefícios. São Paulo: Instituto Socioambiental, 2001. p. 184-193.

DIEGUES, A. C. (Org.). Os saberes tradicionais e a biodiversidade no Brasil. São Paulo: MMA, COBIO, NUPAUB, 2000.

FIGUEROA, R.; MILLS, C. Environmental justice. In: JAMIESON, D. (Org.). A companion to environmental philosophy. Blackwell Publishers, 2001. p. 426-438.

FLORIT, L. F. Conflitos ambientais, desenvolvimento no território e conflitos de valoração: considerações para uma ética ambiental com equidade social. Revista Desenvolvimento e Meio Ambiente, Curitiba, v. 36, p. 255-271, abr. 2016. 
GARUVA. Lei Ordinária $\mathrm{n}^{\mathrm{o}}$ 1981/2017, de 28 de abril de 2017. Cria as diretrizes para promover, reconhecer a auto-identificação e estabelecer políticas públicas para os povos e comunidades tradicionais de Garuva. Garuva: Câmara Municipal, 2017. Disponível em: https://www.camaragaruva.sc.gov.br/camara/proposicao/Leiordinaria/2017/1/0/5666. Acesso em: 22 ago. 2019.

GLOBO ECOLOGIA - 927: Cipozeiros da Mata Atlântica (Parte 1). [S. l.: s. n.], 2010a. 1 vídeo. (10 min). Disponível em: https://www.youtube.com/watch?v=107oi8nQjPw. Acesso em 22 ago. 2019.

GLOBO ECOLOGIA - 927: Cipozeiros da Mata Atlântica (Parte 2). [S. l.: s. n.], 2010b. 1 vídeo. (9 min). Disponível em: https://www.youtube.com/watch?v=05FvQlzYbO8. Acesso em 22 ago. 2019.

GRAVA, D. S. Naturezas, sustentabilidades e desenvolvimento na modernidade brasileira. 2017. Tese (Doutorado em Sociologia) - Instituto de Estudos Sociais e Políticos, Universidade do Estado do Rio de Janeiro, Rio de Janeiro, 2017.

GRAVA, D. S.; FLORIT, L. F. Povos e comunidades tradicionais e conflitos ambientais territoriais em Santa Catarina. In: SEMINÁRIO DE DESENVOLVIMENTO REGIONAL, ESTADO E SOCIEDADE [SEDRES], 4., 2018, Palmas. Anais [...]. Palmas: UFT, 2018. p. 2045-2059.

GRAVA, D. S.; LIMA, C. C.; FLORIT, L. F.; ANTUNES, D. L. Cipozeiras e cipozeiros e conflitos ambientais: relato sobre um grupo em Garuva-SC. In: CONGRESSO BRASILEIRO DE SOCIOLOGIA, 19., 2019, Florianópolis. Anais [...]. Florianópolis: UFSC, 2018. p. 1-19.

HARTLEY, T. W. Environmental Justice: An Environmental Civil Rights Value Acceptable to All World Views. In.: LIGHT, A.; ROLSTON, H. III. (Eds.). Environmental ethics: an anthology. Austrália: Blackwell Publishing, 2003. p. 478-486.

HERCULANO, S. Resenhando o debate sobre justiça ambiental: produção teórica, breve acervo de casos e criação da Rede Brasileira de Justiça Ambiental. Desenvolvimento e Meio Ambiente (UFPR), Curitiba, v. 1, n. 5, p.143-149, 2002.

LASCHEFSKI, K. Licenciamento e equidade ambiental. As racionalidades distintas de apropriação do ambiente por grupos subalternos. In: ZHOURI, A. (Org.). As tensões do lugar: hidrelétricas, sujeitos e licenciamento ambiental. Belo Horizonte: Editora UFMG, 2011. p. 21-59

LEGARDA, A. A.; PARDO BUENDÍA, M. Justicia ambiental. El estado de la cuestión. Revista Internacional de Sociologia (RIS), Córdoba, v. 69, n. 3, p. 627-648, set./dez. 2011.

LITTLE, P. Territórios e povos tradicionais no Brasil: por uma antropologia da territorialidade. Rio de Janeiro: Tempo Brasileiro, 2004. 
MAPA DE CONFLITOS ENVOLVENDO INJUSTIÇA AMBIENTAL E SAÚDE NO BRASIL: resumo dos resultados iniciais (março de 2010). Fiocruz, 2010. Disponível em: http://mapadeconflitos.ensp.fiocruz.br/. Acesso em: 22 ago. 2019.

MARTINEZ-ALIER, J. O ecologismo dos pobres. São Paulo: Contexto, 2007.

MARTINS, J. S. Fronteira: a degradação do outro nos confins do humano. 2. ed. São Paulo: Contexto, 2009.

MMA. Cipozeiros. Brasília: Portal Ypadê, MMA. 2016. Disponível em: http:// portalypade.mma.gov.br/. Acesso em: 13 jul. 2016.

OBSERVATÓRIO DE CONFLITOS AMBIENTAIS. Mapa dos conflitos ambientais. OCA [online], sem data. Disponível em: http://conflitosambientaismg.lcc. ufmg.br/observatorio-de-conflitos-ambientais/mapa-dos-conflitos-ambientais/. Acesso em: 26 abr. 2018.

RAMMÊ, R. S. Da justiça ambiental aos direitos e deveres ecológicos: conjecturas político-filosóficas para uma nova ordem jurídico-ecológica. Caxias do Sul: EDUCS, 2012.

RAMOS, R; HURMUS, M.; BENEVENUTTT, D. N. C.; MELO JUNIOR, J. C. F. A tradição extrativista do cipó-imbé (Philodendron corcovadense Kunth - Araceae) nas comunidades tradicionais de cipozeiros na mata atlântica em Garuva, Santa Catarina. Acta Biológica Catarinense, Florianópolis, v. 4, n. 1, p. 62-70, jan./jun. 2017.

VENTURI, S.; ZAMBONIM, R. M.; ANTUNES, D. L.; TONICELO, R. H. S.; SIMÕES, M. B. A. O artesanato de cipó-imbé em Garuva, SC: uso de ferramentas participativas (linha do tempo) na retrospectiva da atividade com cipó. In: SIMPÓSIO BRASILEIRO De etNobiologia E ETNOECOlOGiA, 6., 2006, Porto Alegre. Anais [...]. Porto Alegre: UFRGS, 2006. 
